\title{
A Correlative Study Between Transrectal Fnac And Histology Of The Prostate For The Detection Of Prostate Carcinoma.
}

\author{
${ }^{1}$ Chayanika Pantola, ${ }^{2}$ Sanjay Kala, ${ }^{3}$ P.K.Singh, ${ }^{4}$ Asha Agarwal, ${ }^{5}$ Sonal Amit \\ 1,3,4,5 Dept of Pathology, 2 Dept. of General Surgery GSVM Medical College, Kanpur, U.P. India pin 208002
}

\begin{abstract}
Aim: To assess the utility of FNAC in diagnosing the prostatic carcinoma
.Material and methods: The study of 121 cases was conducted from year 2006 to 2008. The data was analyzed to assess the utility of FNAC for the diagnosis of carcinoma prostate.

Results: During the study overall sensitivity and specificity of FNAC were $95.23 \%$ and $98.73 \%$ respectively and positive predictive value and negative predictive value were $97.56 \%$ and $97.50 \%$ respectively. The percentage of false positive and false negative cases was $1.26 \%$ and $4.76 \%$ respectively.

Conclusion: The conclusion drawn was that FNAC by trans-rectal route is easiest, accurate, quick method, with minimal discomfort to the patient and outdoor diagnostic procedure for diagnosis of prostatic carcinoma and the result are comparable to that of histopathology.
\end{abstract}

Key words: FNAC, Histopathology, Trans-rectal route, Prostate carcinoma

\section{Introduction:}

Fine needle aspiration cytology is one of the early and versatile techniques that has been added as a diagnostic modality to the armamentarium of the pathologist way back in nineteenth century. Cancer of the prostate has become the most common cancers in male in western countries. It accounts for approximately $20 \%$ of all cancer and for 11-12\% of all cancer death thus ranking second only to lung carcinoma in men in USA and Australia. ${ }^{[1,2]}$

A large number of elderly male populations suffer from prostatism due to enlargement of the prostate as a result of what is now regarded as male climacteric. It is often difficult for examining finger in the rectum to decide whether the enlargement is due to benign condition of the prostate or due to carcinoma of the prostate. It is not an uncommon experience for the surgeon and the pathologist to find an unsuspected carcinoma in the tissue removed under the clinical diagnosis of benign hyperplasia. It is tragically apparent those normal prostates were removed because of suspected carcinoma and because of the lack of adequate method of preoperative diagnosis.

A number of autopsy studies have shown an extremely high prevalence of occult clinically undetected cancer of the prostate. On careful examination, cancerous foci have been found at autopsy in approximately $80 \%$ of men over the age of 80 year or above. It has been estimated that four fifth of these cancers are truly occult but that one fifth have the potential to become clinically manifest and eventually lethal. Yet the incidence of clinical cancer, i.e. the new cases of diagnosed per year, equals only just over $1 \%$ of the prevalence found in autopsy studies. ${ }^{[3]}$

Thus a large proportion of clinically significant cancers remain undetected. At the time of diagnosis, almost half of the cancers are advanced and a little over half are localized and potentially curable. These data emphasize the need for improvement in the preoperative diagnosis and detection of prostate cancers. Problem arises when advice is sought for symptoms of prostatism and the gland presents equivocal findings. Early hard prostate is not a carcinoma, though the impressive teaching dictum is-" it is carcinoma, until proved otherwise", at the same time every firm or soft prostate is not free from carcinoma as soft carcinoma are also known.

Ferguson in 1930 first described the diagnosis of prostate cancer by trans-perineal aspiration biopsy. ${ }^{[4]}$ In 1960 Franzen developed a finger guide and use flexible small caliber needle to sample the prostate trans-rectally. ${ }^{[5]}$ Since then trans-rectal aspiration biopsy of the prostate has been preferred for diagnosing various prostatic lesions especially prostatic cancer.

II. Material and methods:

The study of 121 cases of various prostatic lesions was conducted. Cases were selected after proper history, examination including digital rectal examination and informed consent about the procedure, and were subjected to FNA by trans-rectal route. No local anesthesia was given during the procedure.

FNA done by disposable long 22/23 gauze needle with stylet which fit in the Franzen canula. Patient lying on left lateral position and Franzen guide canula was fixed to index finger and upon obtaining the aspirate smeared on slide and fixed in 95\% alcohol and stained by haematoxylin and eosin. The smears were examined and categorized as benign nodular hyrerplasia, benign nodular hyperplasia with chronic prostatitis and 
adenocarcinoma. A corresponding true cut biopsy or whole excised specimen of prostate was subjected for histopathological examination which was fixed in $10 \%$ formalin, processed and then cut and stained with haematoxylin and eosin.

\section{Results:}

Prostate FNAC of 121 cases were studied along with their histology. Out of these, 78 cases (64.47\%) were diagnosed as benign prostatic hyperplasia, 02 cases (1.65\%) were diagnosed as benign prostatic hyperplasia with chronic prostatitis and 41 cases $(33.88 \%)$ were diagnosed as malignant (adenocarcinoma prostate) [Tab-1]. The biopsy tissue of the same cases either exicisional or true cut revealed 71 cases $(58.67 \%$ ) cases of benign prostatic hyperplasia and 08 cases (6.61\%) of benign prostatic hyperplasia with chronic prostatitis and malignancy ( adenocarcinoma prostate) was diagnosed in 42 cases (34.71\%).

During histopathological examination, out of 78 cases diagnosed as benign prostatic hyperplasia by FNAC, 70 cases were diagnosed as benign prostatic hyperplasia, 06 cases as benign prostatic hyperplasia with chronic prostatitis and 2 cases as malignant (adenocarcinoma prostate). So percentage of false negative cases is $4.76 \%$ while out of 41 cases diagnosed as positive for malignancy by FNAC one case was diagnosed as benign prostatic hyperplasia so percentage of false positive cases was $1.65 \%$. Overall sensitivity was $95.23 \%$ and specificity was $98.73 \%$ with positive predictive value and negative predictive values were $97.56 \%$ and $97.50 \%$ respectively.

\section{Discussion:}

$33.88 \%$ (41out of 121) patients in our study were diagnosed of prostatic carcinoma during FNAC.and no difficulties have been experienced in distinguishing benign from malignant prostatic cells in satisfactory smears. Esposti PL et al in 1974 reported in his study the cytological results with transrectal aspiration biopsy of the patients after 20 year of experience. ${ }^{[6]} \mathrm{A}$ good correlation was found between cytological findings and histological controls in 350 patients. Overall accuracy was $96 \%$ and $93 \%$ specificity for benign and $97 \%$ for cancer. Similarly Melograna et al in 1982 reported confirmation of diagnosis occur $91 \%$ time, $96 \%$ with BPH, $77 \%$ with carcinoma and $100 \%$ with prostatitis. ${ }^{[7]}$

Hosking et al in 1983 conducted a prospective study during 2 year period comparing the accuracy of trans-rectal FNA with that of trans-perineal needle biopsy in diagnosis of prostatic carcinoma. ${ }^{[8]}$ With increasing experience the accuracy of aspiration of aspiration was found to be at least equal to that of biopsy.

Noguchi et al in 1989 perform 86 cases of cytological diagnosis of prostate by FNA. ${ }^{[9]} 25$ patients were diagnosed as positive in cytology and were admitted and further evaluated with conventional needle biopsy followed by histological examination. Then 18 of them were diagnosed with prostatic carcinoma. False positive rate and false negative rate were $10 \%$ and $3 \%$ respectively.

Mondal et al in 1990 carried trans-rectal FNA by Franzen technique in 126 patients having enlarged prostate. ${ }^{[10]}$ Comparisons of aspiration cytology with histopathlogy, serial serum acid phosphatase, repeat aspiration cytology after hormonal therapy with or with out orchiectomy and clinical follow up showed accuracy of cytologic diagnosis of $98.4 \%$ with false negative was $1.6 \%$. There was no false positive case.

Similarly Das et al in 1990 reported $91.4 \%$ correlation between clinical and cytological findings. ${ }^{[11}$ Ou et al reported accuracy rate of $89.7 \%$ by histology and $69.2 \%$ by cytology. ${ }^{[12]}$ Aryya et al reported $99 \%$ accuracy rate in identification of benign or malignant nature of disease. ${ }^{[13]}$ Singh et al in 1997 reported $98.33 \%$ and $81.81 \%$ accuracy for benign and malignant lesion respectively. ${ }^{[14]}$

Al-Abadi compared the result of histology and cytology in 246 patients, 142 with benign lesions, 103 with prostatic carcinoma and 3 with atypical prostatic hyperplasia. ${ }^{[15]}$ FNA procedure gave a sensitivity of $98 \%$, whereas core biopsy had a sensitivity of $96 \%$.

Similar observations have been reported by Couture et al, Kline et al, Ljung et al, Koltz et al and Brenner et al . $[16,17,18,19,20]$ Al Abadi reviewed the pertinent literature, notably papers by Bruin et al and his own previous publication and concluded that FNA was more accurate, less tedious to the patient and much cheaper than the core biopsy. ${ }^{[21]}$

Hermida et al reported sensitivity of $96 \%$, specificity $96 \%$, positive predictive value $91 \%$, negative predictive value $93 \%$ and efficacy $92 \%$. ${ }^{[2]}$ Saleh AF et al reported the sensitivity for detection of prostatic carcinoma was $88 \%$, specificity was $93 \%$ and diagnostic accuracy $91.7 \%$. ${ }^{[23]}$ Planlles GJ et al concluded that male over 75 years old with Prostate specific antigen (PSA) $>30 \mathrm{ng} / \mathrm{ml}$ or PSA $>20 \mathrm{mg} / \mathrm{ml}$ and suspicious digital rectal examination the cytological results were $100 \%$ positive. ${ }^{[24]}$ So it is concluded that FNA by trans-rectal route is easiest, accurate, quick method with minimal discomfort to patient and outdoor diagnostic procedure in diagnosis of various prostatic lesions. The procedure may be used as an efficient primary screening tool for early detection of malignancy and in selected patients it may be used as an alternative to core needle biopsy for the diagnosis, treatment planning and follow up. 


\section{References:}

[1] Bonnett A, Roder D, McCaul K, Milliter L. Epidemiology of cancer in South Australia. Adeliade: South Australian Cancer Registry, 1992.

[2] Nomura A M Y, Kolonel L N. Prostatic cancer: a current perspective. Epidemiol Rev 1991; 13: $200-207$.

[3] Scadino P T, Weaver R, Hudson M A. Early detection of prostatic cancer. Hum Pathol 1992; 23: $211-222$.

[4] Ferguson R S. Prostatic neoplasms: Their diagnosis by needle puncture and aspiration. Am J Surg 1930; 9: 507-511.

[5] Franzen S, Giertz G, Zajicek J. Cytological diagnosis of prostate tumors by transrectal aspiration biopsy: a preliminary report. Br J Urol 1960; 32: 193-196.

[6] Esposti P-L. Aspiration Biopsy Cytology in the Diagnosis and Management of Prostatic Carcinoma. Stockholm, Stahl and Accidenstryct, 1974.

[7] Melograna F, Oertel Y C, Kwart AM. Prospective controlled assessment of fine needle prostatic aspiration. Urology 1982 Jan; 19(1) : 47-51

[8] Hosking D H, Paraskevas M, Hellsten O R, Ramsey E W. The cytological diagnosis of prostatic carcinoma by trans-rectal fine needle aspiration. Urol 1983 May; 129(5): 998-1000.

[9] Noguchi K, Moriyama M, Miura T, Kinoshita Y, Kubota Y, Hosaska M. Usefulness of fine needle aspiration cytology in the diagnosis of prostatic carcinoma. Hinyokika Kiyo. 1989 Mar; 35(3): 399 - 401.

[10] Mondal A, Ghosh E, Ghose A. The role of transrectal fine needle aspiration cytology in the diagnosis of prostatic nodules suspicious of malignancy - a study of 126 cases. Indian J Pathol. Microbiol. 1990 Jan; 33 (1): 23 - 29.

[11] Das D K, Hedlund P O, Lowhagen -T, Stanley M W, Esposti P L . Improved early detection of recurrence in prostatic carcinoma following hormonal therapy. Combined use of palpation and fine needle aspiration cytology. Urology 1990 Oct; 36 (4): 341 - 45.

[12] Ou YC, Wu HC, Yang CR, Chang MC, Chang CL, Hwang TI, Chang CH. A comparison of transrectal fine needle aspiration and biopsy of prostatic lesion. Zhonghua Yi Xue Za Zhi (Taipei). 1992 Jul; 50 (1): 46-51.

[13] Aryya N C, Yadav R K, Singh P B, Khanna S. Pandey K. Fine needle aspiration cytology in the diagnosis of prostatic enlargements. Indian J Cancer. 1992 Dec; 29 (4) : 186 - 91.

[14] Singh N, Shenoi UD, Raghuveer CV. FNAC and transabdominal ultrasonography in the diagnosis of prostatomegaly. Indian J Pathol Microbiol. 1997 Oct; 40 (4) : 473-9.

[15] Al-Abadi H. Fine needle aspiration biopsy vs. ultrasound guided transrectal random core biopsy of the prostate: Comparative investigation in 246 cases. Acta Cytol. 1997; 41: 981-86.

[16] Couture M L, Freund M, Katubig C P Jr. The isolation and identification of exfoliated prostate cells from human semen. Acta Cytol. 1980; 24: 262-67.

[17] Kline TS, Kohler FP, Kesley DM. Aspiration biopsy Cytology. Its use in diagnosis of lesion of prostate gland. Arch Patho / Lab Med 1982; 106: 136 - 39.

[18] Ljung B M: Fine needle aspiration biopsy of the prostate gland. A study of 103 cases with histologic follow up. J. Urol. 1986; 135: 955 -57 .

[19] Klotz L H, Shaw P A, Srigley J R. Transrectal fine needle aspiration and truecut needle biopsy of the prostate gland: a blinded comparison of accuracy. Can J Surg.1989; 32: 287-89.

[20] Brenner D W, Ladaga L E, Fillion M B, et al. Comparison of transrectal fine needle aspiration cytology and core needle biopsy in diagnosis of prostate cancer. Urology.1990; 35: 381-84.

[21] Bruins J L, Lycklama A, Nijeholt A A B, et al. The value of fine needle aspiration biopsy in comparison with core biopsy histology. World J Urol. 1989; 7: 2-26.

[22] Hermida Perez JA, Ochoa Urdangarain O, Ramos Rodriguez AV, Acost Bernad I, Vento Remedios T, Mesa Borroto D et al. Fine needle aspiration cytology in the diagnosis of prostate cancer. Results. Arch Esp Urol. 2001 Jan- Feb; 54 (1): 23-33.

[23] Saleh Af, Nahar Rahman AJ, Salam MA, Islam F. Role of fine needle aspiration cytology (FNAC) in the diagnosis of prostatic lesions with histologic correlation. Bangladesh Med Res Counc Bull.2005;31(3):95-103. .

[24] Planelles Gómez J, Beltrán Armada JM, Alonso Hernández S, Tarín Planes M, Beamud Cortés M, Gil Salom M. Value of transrectal FNA in the diagnosis of prostate cancer in elderly patients. Actas Urol Esp.2008;32(5):485-91.

Tab- 1) Correlation between FNA findings and histological findings of different lesions of prostate

\begin{tabular}{|l|l|l|l|l|}
\hline FNA Diagnosis & \multicolumn{3}{|c|}{ Histological Diagnosis } & Total \\
\cline { 2 - 4 } & $\begin{array}{l}\text { Benign } \\
\text { prostatic } \\
\text { hyperplasia }\end{array}$ & $\begin{array}{l}\text { Benign } \\
\text { prostatic } \\
\text { hyperplasia } \\
\text { prostate with } \\
\text { chronic } \\
\text { prostatitis }\end{array}$ & $\begin{array}{l}\text { Adenocarcinoma } \\
\text { prostate }\end{array}$ & \\
\hline $\begin{array}{l}\text { Benign prostatic } \\
\text { hyperplasia }\end{array}$ & 70 & 06 & 02 & 78 \\
\hline $\begin{array}{l}\text { Benign prostatic } \\
\text { hyperplasia with } \\
\text { chronic prostatitis } \\
\begin{array}{l}\text { Adenocarcinoma } \\
\text { prostate }\end{array}\end{array}$ & 00 & 02 & 00 & 02 \\
\hline Total & 01 & 00 & 40 & 41 \\
\hline
\end{tabular}

